\title{
A COGNITIVE-SEMANTIC ANALYSIS OF THE ENGLISH LEXICAL UNIT IN
}

\author{
Ignasi Navarro i Ferrando \\ Universitat Jaume I
}

\begin{abstract}
The standard semantic description of English in has been traditionally understood as a matter of geometric configuration of the participants in the spatial relation. The landmark is conceived of as an area or volume, or as a three-dimensional entity, the topological relation of inclusion being emphasised. The landmark may also be understood as a MEDIUM configuration, in opposition to the geometric conception based upon the idea of container. Other authors pose a meaning based on the relative function of the participants, i.e. the control of the container over the contained entity. Finally, dynamic uses are acknowledged, but the nature of the motion expressed has not been described.

Our notion of conceptual schema - a gestalt configuration where some elements may be focused upon - refers to the central meaning from which other senses are derived. Our aim is to provide not just a list of uses, but a semantic structure that accounts for all the senses in terms of a radial network. The network extends through three conceptual regions that stand for topological, functional, and force-dynamic dimensions of the conceptualisation of the relationship. Three main imaginative procedures are described for meaning extension: First, shifts of the conceptual schema (rotation, profiling, semantic bleaching), second, partial sanction, which focuses on one or more dimensions (specialisation of meaning), and finally metaphorical mappings, which account for figurative meaning and idiomatic use.
\end{abstract}

RESUMEN. La descripción semántica de la palabra inglesa in aceptada hasta hoy se centra en la configuración geométrica de los participantes en la relación espacial. El hito (landmark) se concibe como área, volumen, o sencillamente como una entidad tridimensional, con énfasis en la relación topológica de inclusión. El hito también se ha entendido como MEDIO, en contraposición a la idea de recipiente (container). Otros autores han propuesto un significado basado en la función relativa de los participantes, es decir, el control del recipiente sobre el contenido. Por último, se reconocen usos dinámicos pero no se ha descrito el carácter del movimiento expresado.

En este artículo, la noción de esquema conceptual - configuración gestáltica en la que se focalizan ciertos elementos - se refiere al significado central del que se derivan otros. Nuestro objetivo no es presentar una mera lista de acepciones, sino explicarlas mediante una estructura semántica del tipo de una red radial extensiva a tres regiones conceptuales que expresan las dimensiones de la relación espacial: topológica, funcional y de dinámica de fuerzas. La extensión de significado se explica mediante tres procedimientos imaginativos: modificación del esquema conceptual (rotación, perfil, decoloración semántica), sanción parcial, que resalta una o más de las dimensiones (especialización del significado) y, por último, proyecciones metafóricas, que dan cuenta de los usos metafóricos e idiomáticos. 


\section{Introduction}

One of the main issues in Cognitive Linguistics research is the description of prepositional semantics (Boers 1996; Brugman 1980; Cuyckens 1988, 1993, 1994; Dewell 1994; Dirven 1981, 1989, 1993; Herskovits 1986; Hawkins 1984; Lindner 1983; Radden 1981; 1989; Sandra \& Rice 1995; Schulze 1991, 1994; Vandeloise 1991, 1994; Navarro i Ferrando 1998, to appear). In relation to this issue, two main positions are observed:

a) Prepositional meaning is defined as a core sense. Within this position we find two trends:

1. All the uses of a preposition are reduced to a core sense, which is the one introduced in the lexicon. The context provides other aspects of meaning which do not belong to the preposition (Leech 1969; Bennett 1975).

2. There is one core meaning that occurs in a variety of contexts. These contexts introduce nuances of meaning that can be assigned to the preposition, but the core sense is in all of them (Miller \& Johnson-Laird 1976; Herskovits 1986; Wierzbicka 1993).

b) Prepositions are polysemous: There is a prototypical sense and other non prototypical senses. Within this position there are two approaches:

1. There is a preference rule system that determines the prototype (Ciencki 1989).

2. The different senses of a preposition can be derived from a basic image-schema by means of family resemblances and image schema transformations (Brugman 1980; Lindner 1983; Hawkins 1984; Lakoff 1987; Cuyckens 1988, 1993, 1994, 1995; Vandeloise 1991; Schulze 1991, 1994; Dewell, 1994; Boers 1996; Navarro i Ferrando 1998, to appear).

Brugman (1980) and Lindner (1983) first used radial networks and imageschema transformations in their descriptions, in the context of an emergent semantic theory known as Cognitive Grammar (Langacker 1987, 1991a, 1991b), also called Cognitive Semantics (Lakoff 1987). In Cognitive Grammar, spatial concepts are relational, and need two other concepts for conceptualisation to take place. These two entities, conceptualised in the same construal event as the relational concept itself, are called trajector and landmark, and bear an asymmetrical relationship. The former is the localised or foregrounded entity, whereas the latter functions as localiser, background or reference point.

However, other aspects of spatial semantics have not yet been completely agreed upon ${ }^{1}$. That is the case of the role of landmark dimensionality. Thus, it is normally assumed that one of the semantic differences between the units at, on and in resides in

1. An interesting reflection on a metalanguage for the description of spatial semantics is found in Sinha \& Thorseng (1995). 
the different types of dimensionality that their landmarks impose on the conceptualisation (Lindkvist 1950, 1976; Leech 1969; Bennett 1975; Hawkins 1984; Herskovits 1986; Quirk et al. 1985; Cienki 1989; Cuyckens 1993; Hottenroth 1993). This approach leads the analysts to $a d$ hoc solutions when they try to explain uses like at sea, or at a surface - where the landmark should be a point - or when an explanation is needed why these three prepositions can be used equally with such landmarks as point or period. Let us consider the following examples ${ }^{2}$ :

1.a. Moreover, $\mathrm{C}^{\prime}$ obviously meets any line $\mathrm{f}$ in a single point.

1.b. Ignorance on this point has caused a great deal of needless anxiety.

2.a. Now if one hydrogen atom were placed at the surface of a large sphere of hydrogen atoms, it would...

2.b. There was something in the surface for the bowlers throughout the day, ...

3.a.... the Bank of England disappointed traders and pitched the next auction on February 22, at the ten-year area.

3.b. ... two other men stood on a gray cement area next to the pool on my left.

It is shown that these prepositions can be used with any kind of landmark dimensionality (point, surface, area). According to these facts, landmark dimensionality - a semantic feature of one of the concepts involved in the construal, but not a semantic feature of the relationship - might be disposed of for semantic analysis of prepositions in favour of other aspects that have to do more directly with the spatial relationship itself. In the case of in, landmarks may have one, two or three dimensions (Herskovits 1986: 148; Hottenroth 1993: 214-215), which in fact tells nothing about the relationship expressed. Other prepositions like at can also have three-, two- and one-dimensional landmarks conceptualised as such, though this fact has been frequently denied.

Otherwise, if we deal with relational concepts, which requires two entities involved simultaneously in a relation, the kind of equipment for analysis should include theories of how an entity is conceptualised in some kind of relation with another entity. This seems a truism, but it has been drawn to a secondary position in spatial semantic analyses which give pre-eminence to landmark dimensionality. According to this observation, there are at least three semantic dimensions that can help determining the kind of spatial relationship established between two entities in human conceptualisation:

Topology: First, human beings perceive objects visually, which gives the speaker clues for establishing and conceptualising topological relations like coincidence, contact, inclusion, proximity, and the like ${ }^{3}$.

2. These examples have been taken from the Web Concordancer (English) at http://vlc.polyu.edu. $\mathrm{hk} /$ scripts/concordance/WWWConcappE.htm

3. Topology has been widely used in the description of spatial semantics, and it is an accepted and uncontroversial aspect of spatial semantics. 
Force-dynamics: Secondly, human beings have experience of self-motion and object motion, which provides the clues for conceptualising patterns of interaction in terms of force-dynamics ${ }^{4}$.

Function: Finally, human beings have experience of the effects of interaction, as well as the consequences of those effects for survival and well being. This kind of experience may be projected onto other entities -animals and objects- so that the functional patterns conceptualised on the basis of human interaction are also used for the conceptualisation of spatial relationships between those entities.

The role of function in spatial relationships is not a new idea in Cognitive Semantics (Miller \& Johnson-Laird 1976: 375ff.; Vandeloise 1991, 1994; Dirven 1989: 524; Cuyckens 1993: 48-49), but the anthropocentric character of its conceptualisation has possibly not been emphasised sufficiently. Functions are conceived from a human perspective, in terms of human biological and physiological configuration, as well as human values, abilities and capacities. It is relevant to recall here the experientialist character of human cognition and semantics as opposed to objectivist positions. As Lakoff and Johnson (1999: 37) put it "the body is not merely somehow involved in conceptualisation, but is shaping its very nature". This kind of phenomenological embodiment implies the three dimensions of human experience: topology, force-dynamics, and function.

In the present paper, I will try to offer a coherent account of the English preposition in as a multimodal semantic structure ${ }^{5}$ based on these three configurations. Other studies have focused their attention on this preposition in other languages like French or Dutch (Vandeloise 1994; Hottenroth 1993; Cuyckens 1993), but there is still lack of a thorough account of in in English. Lindkvist (1950) and Herskovits (1986) provide lists of contexts where the preposition appears, but they are asystematic, and in any case no explanation of meaning is attempted other than the three-dimensionality of the complement and the relation of topological inclusion.

The semantic structure of in has been traditionally understood as a matter of geometric configuration of the objects or participants in the relation. The standard description of its meaning implies that the landmark is conceived of as an area or volume by native speakers (Lindkvist 1950; Bennett 1975; Quirk et al. 1985; Dirven 1989), or as a three-dimensional entity (Leech 1969). This geometric conception is complemented by topological judgements in most standard descriptions. In some descriptions, thus, the topological relation of inclusion is emphasised (Miller \& Johnson-Laird 1976; Herskovits 1986; Cienki 1989), though this inclusion may be partial.

In opposition to the geometric conception based upon the idea of container, the landmark may be understood as a MEDIUM configuration (Hawkins, 1984, 1988).

4. A comprehensive account of the role of force-dynamics conceptualisation in language expression can be found in Talmy $(1983,1988)$.

5. Multimodal semantics for prepositions has been proposed by Deane (1993). 
Vandeloise (1994) rejects the geometric description altogether, and posits a meaning based on the relative function of the participants. The control of the container over the contained object is emphasised. He admits of a certain degree of relevance for the topological relation of inclusion as well.

Finally, dynamic uses are acknowledged by most of the authors, but the nature of the motion is not described.

In this paper, the notion of conceptual schema will be used to refer to the central and primary meaning from which other senses are derived ${ }^{6}$. The conceptual schema is a gestalt configuration where some elements may be focused upon, whereas others constitute a background. The aim of this work is to provide not just a list of uses, but a proposal for a coherent semantic structure that could account for all the senses described in terms of a radial network, with a central sense and peripheral senses. Thus, the network extends through three conceptual regions or configurations that stand for topological, force-dynamic, and functional aspects of the conceptualisation of the relationship. Among the mechanisms that produce polysemy, three main imaginative procedures will be described for extension of meaning: First, shifts that imply a slight modification of the conceptual schema, in terms of schema rotation, profiling of particular elements or parts, and/or semantic bleaching of some element or part. Second, partial sanction of the conceptual schema, which profiles one or more configurations and leaves the rest in the background, in a process called specialisation of meaning. Finally, metaphorical mappings from the physical domain onto abstract domains will account for figurative meaning.

The examples used for the analysis have been drawn from the Brown Corpus of American Written English (Francis and Kucera 1961) including the corpus coding, e.g. A13:56 (text type text number: line number).

\section{Fuzzy syntactic categorisation of in}

This unit appears in prepositional constructions as described by the grammar (Quirk at al. 1985: 658-661), i.e. as the head of a postmodifier Prepositional Phrase in the constructions $N p$ Prep $N p$ and Adj Prep $N p$, with prepositional verbs in the construction Verb Prep Np, or as the head of an adjunct Prepositional Phrase in the construction Verb Prep Np. But it also appears as a nominal suffix and prefix, (drivein, inboard, inlet, inmate, sit-in, inset, insight, etc.), as an adjectival suffix and prefix,

6. The notion of conceptual schema develops from different perspectives, e.g. as 'schema' (Talmy 1983), 'impetus' (Vandeloise 1991), 'complex primitive' (Vandeloise 1994), 'central schema' (Dewell 1994), 'central reference point' (Rice 1996), and 'superschema' (Langacker 1987). This conceptual schema is the result of the abstraction and schematisation of particular perceptive features associated with the use of a particular linguistic unit. It constitutes the core node of a polysemy network. It is sanctioned, at least partially, by all the senses of a unit. It is the sense which is most economically related to all the rest. 
(in-person, in-state, inboard, inborn, indoor, inland, inward, etc.), as an adverbial suffix and prefix, (herein, hereinafter, indoors, inward, inwardly, inshore, etc.), as an adjectival stem, (inner, innermost, etc.), as an adverbial particle of phrasal verb constructions (...a sailor returns, unrecognized, and gets done in by his wife C07:109), as a nominal stem (inning) or noun. The high degree of grammaticisation is shown by the attachment of the particle to the stem, in the formation of adjectives (blacked-in, boxed-in, built-in, fade-in, fill-in), or nouns (drive-in).

It is evident that the unit in does not present a homogeneous syntactic behaviour as preposition. This kind of behaviour is by no means unique to this unit, but to a higher or lower degree characterises most of those units called prepositions. Homogeneous word classes do not seem actually to occur (Taylor 1989, 1994). On the other hand, one single unit does not necessarily belong only to a particular syntactic category. As $\mathrm{T}$. Givón remarks, natural classes are seldom as neat as logical classes, and the class of prepositions is to be considered as a natural class more than a logical one:

\footnotetext{
“...First, not all members of a natural class abide by rigid membership criteria to the same degree. Second, membership is most commonly determined by a cluster of criteria. Some of these criteria are more important ('central') than others, but none is absolutely inviolable by itself. Consequently, natural classes do not resemble logical classes; their definitions, and thus their boundaries, are a bit fuzzy, they allow some slop, ambiguity and overlap." (Givón, 1993: 52)
}

It can be argued that the central criterion for the category of prepositions is the use in the prepositional construction, since it is the most common feature (at, from, with, onto, or into, are always the head of a PP). On the other hand, Givón notices that "the population of a natural class is often best characterised by its frequency distribution curve, where - with respect to any criterial feature or cluster of features the most prototypical members are closest to the population mean" (Givón, 1993: 53). In the set of prepositions, the majority of members of the category shares the syntactic functions of the across-group (about, across, along, around, beyond, behind, besides, inside, and past), which also appear in adverbial function. A minority of members are less typical, since they overlap with other categories at both ends of the periphery (up and down at the lexical end, or of, and to at the grammatical end as case markers). Nevertheless, if other criteria are adopted as central, for instance the feature of having subordinating function, a different set of units would result as typical members of the category, and some of the items analysed as prepositions would be considered as deviant subordinators. Likewise, if we analysed adverbs, some of our prepositions, would be deviant adverbs; and so on. In our case, in belongs to a minority group within the category of prepositions, that is, those units that show the highest degree of morpho-syntactic versatility.

Syntactic approaches deal with semantics as a subsidiary component to syntax (e.g. Chomsky 1965) whereby semantic features of a lexical entry play the function of selectional restrictions in syntax. For this reason, semantic markers are reduced to a 
minimum set of primitive features. According to this approach, the search for economy in the lexicon leads to the postulation of a core sense for each preposition. Variations in meaning belong to the context, not to the unit itself. However, the contexts considered by this approach are considerably limited, since verb particles (in phrasal verbs and prepositional verbs), as well as case markers (of, to, for, by) are listed in the lexicon under the entries of the verbs they occur with, which does not require any semantic analysis. In other contexts, the core sense is posited under the assumption that it is common to all the occurrences of a unit, and is defined in terms of binary semantic markers. Analyses from this perspective, such as Bennett's (1975), reduce the semantic scope of in to LOCATIVE INTERIOR. Conversely, Brugman (1981), Lakoff (1987), and Dewell (1994) showed that the alleged core sense does not appear at every occurrence of the word over. A central or prototypical sense is posited that bears the largest number of features belonging to that category, in contrast to peripheral senses that are the result of meaning extension. The semantic structure of over could explain the sense of the prefix in overlook, the sense of the particle in look over, as well as the sense of the adverb in They marched over. Accordingly, Lindner (1983) showed how a semantic chain could also explain particle meaning in phrasal verbs and prepositional verbs. She set aside the false idea that those particles are void elements of lexical entries for verbs listed in the lexicon. Semantic structure can be accounted for in terms of family resemblances, semantic chains, and prototypical senses that give birth to more peripheral ones. Syntactic diversity in the usage of particular units is caused by variations in construal that are expressed by diverse morpho-syntactic constructions, but not by the existence of homonym lexical entries.

Following these assumptions, the semantic structure of the lexical unit in is deemed to be stable through all its morpho-syntactic distribution.

\section{Conceptual schema for in}

\subsection{General conceptual image-schema}

One of the preconceptual image-schemas posited by Johnson (1987) is the container schema. It is so pervasive that it prompts the emergence of a concept on its own. Thus, it becomes the primigenial conceptual schema for the concept expressed with the unit IN. Nevertheless, that primary conceptual schema undergoes a set of imaginative semantic shifts, partial sanctions, and metaphorical mappings that result in the development of polysemy through usage. Therefore, though the origin of the concept in may be looked for in the container schema, a relation of identity between both notions should not be assumed.

The basic logic of the container schema (Lakoff \& Johnson, 1980; Johnson, 1987; Lakoff, 1987; Fornés \& Ruiz de Mendoza, 1996) could be reinterpreted in terms of a summation of topological, force-dynamic, and functional configurations. It is 
assumed that children's experience in relation to containers provides the first clues for the assemblage of these configurations. This may suggest that the container schema can become a full concept on its own. Preconceptual are indeed the topological, functional, and force-dynamic image-schemas that conflate in the container imageschema ${ }^{7}$. According to this view, the primigenial conceptual schema for $i n$, as derived from bodily experience, would involve the following elements (see fig.1):

1. The trajector is a finite entity. Being finite is what makes it possible for it to be contained in another entity. Human beings, animals, and objects are bounded entities whose finiteness is given by their boundaries. Gases, fluids and massive entities are finite as long as a certain amount of them is taken into consideration. Very few entities are non-finite, for instance, the universe, the ocean, the heavens, the vacuum, the infinite itself, and very few more, if any. Therefore, almost anything can be conceptualised as the trajector of $i n$.

2. The landmark is an object or entity which defines the boundaries of a region, and so determines some limits and capacity for that region. Therefore, it defines an interior space where the trajector is located. The boundary is not a complete closure of the interior region, so that an access/exit exists through which entities may enter or exit that interior region.

3. According to the force-dynamic configuration, the trajector may move within the interior region defined by the landmark. It defines a trajectory either from the exterior of the landmark to find its end in the interior, or within that interior. Thus, movement of the trajector may affect the interior of the landmark. In any case, the force-dynamic configuration of in precludes movement towards the exterior region defined by the landmark's boundaries. The access to the interior region is not on the bottom of the container, which would cause the trajector to fall out of the landmark by the effect of gravity. Only with trajectors that are not under the effect of gravity (gas) could the exit be in the bottom part of the landmark (e.g. smoke in the upside down glass).

4. According to the topological configuration, the trajector must be smaller than the landmark. Perceptually, both coincide in space, so that the space occupied by the trajector is also occupied by the landmark, but not vice-versa. This is so, as long as, prototypically, the interior region defined by the landmark cannot be perceived from the outside, and is therefore conceptualised as part of the landmark itself.

5. The functional configuration defines the roles of trajector and landmark with respect to each other. Since the landmark is seen as an entity that both prevents the trajector from moving freely and impedes access of other entities to it, the roles are defined by a control relationship, whereby the landmark controls the

7. Recent research on the nature of the container schema points out its complex character from a different perspective by noticing that other image-schemas, like the full-empty schema, might be subsidiary to it (Fornés \& Ruiz de Mendoza 1996; Peña 1997). 
trajector. This control may adopt two forms: reclusion or protection, depending on the aspect emphasised. In any case, the relationship defined by in never allows for control of the trajector over the landmark.

6. The landmark's active zone ${ }^{8}$ is the invisible part, which defines the region called interior. The trajector lacks a definite active zone, because all of it is involved in the relationship.

7. Since in may be used with the universe, the world, etc. as containers where all life takes place, the scope of predication may be maximal. The trajector may be a concept at a smaller scale than the landmark (molecules in the world).

This conceptual schema (ENCLOSURE) constitutes sense 1 in the network, and is instantiated in a wide range of possibilities. The following are the most salient:

a) Manmade containers such as glasses, vases, plates, bowls, cups, jugs, drawers, pans, pots, deposits, basins, tins, etc. - the ice cubes tinkling in a glass (P05:28).

b) Natural containers like caves, wells, shells, etc. - a sniper's nest in a mountain cave (K03:39).

c) Vehicles for transport like cars, buses, trains, ships and boats, aeroplanes, etc. -J. Pierpont Morgan had come in his private train to San Francisco (E11:49), Helva was unconditionally graduated and installed in her ship (M05:93)

d) Human and animal bodies, as well as their parts, as containers. - all the hydrogen in my body (D13:17), atoms in my body (D13:31).

e) Buildings, dwellings, houses, parts of buildings, rooms, dependencies, etc. - you are sitting in a room (C02:68), She lived in an ultra-modern house (R02:65).

f) Envelopes, sheaths - the conditions in the anode sheath. (J02:15)

motion only within

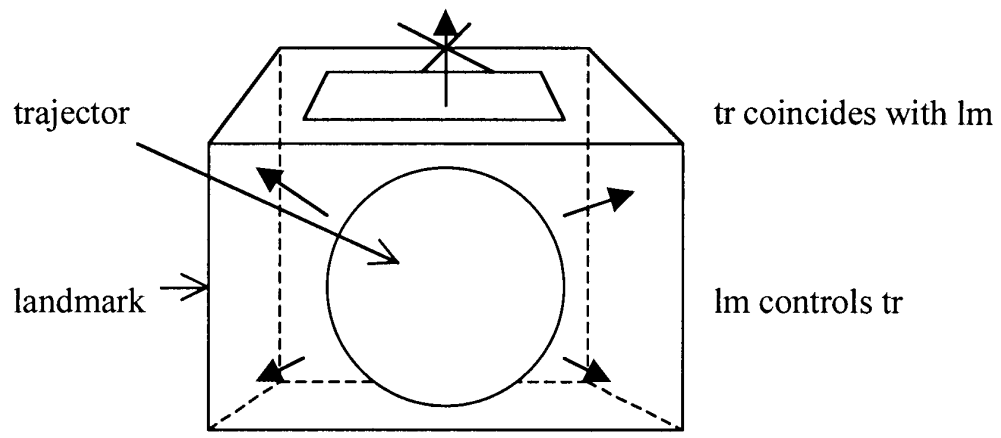

Figure $\mathbf{n}^{\mathbf{0}}$. 1: Conceptual schema of in: Enclosure (sense 1). The arrows show the direction of potential motion. The square on the top side of the cube represents the access to the interior region. The cube boundaries represent the landmark boundaries.

8. The concept of active zone is related to the concept of search domain, as used by Miller \& JohnsonLaird (1976). For further illustration of this concept see Langacker's account (1991: 189-201). 


\subsection{Shifts of the conceptual schema}

Shifts imply a slight modification of the gestalt, in the sense that some elements or parts of it are profiled, and others fade out. The following senses of in result:

Sense 2: Partial enclosure. The boundaries defined by the landmark are conceptualised as incomplete, so that part of the trajector is visible. Therefore, control is incomplete, and the sense of protection prevails over the sense of seclusion. Topological coincidence might not be complete, and movement of the trajector towards the exterior is not completely barred (see fig. 2). This sense of in occurs with landmarks like corner, frame, rack, shelter, door, ceiling, seat, lap, balcony, clothes, beds, chairs, shoes, trees, etc. - The blonde's nude body was in bed (F09:111), the golden glow in a corner (G14:3)

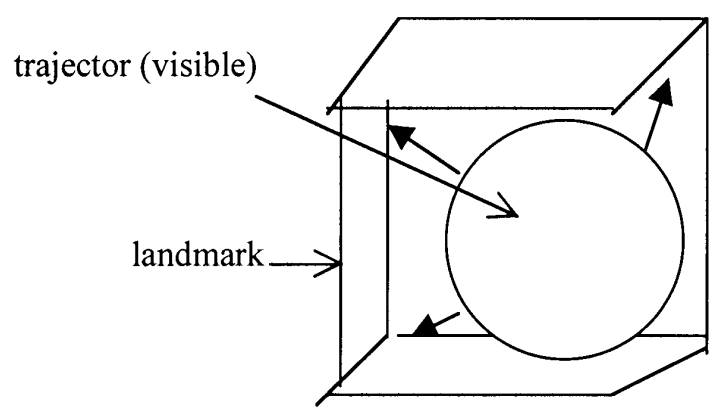

motion only within

tr coincides with $1 \mathrm{~m}$ Im controls tr (protection)

Figure no. 2. Partial enclosure(sense 2)

Sense 3: Interior region is landmark. The spatial region limited by the landmark is profiled, so that it takes on the role of the landmark itself. It is referred to as a space with assumed boundaries, though not salient, that define it as an interior region. Landmarks denote the space within a container, such as interior, space, hole, inside, slot, crack, hollow, leak, doorway, etc., as well as in expressions like in lieu of, in place of - ...English language that has been excellently dubbed in place of the Russian dialogue. (C01:102), ...maneuvering the car around in a very narrow space (L04:165), all the tappet bars [...] can be replaced in the same slots (E07:75).

\subsection{Metaphorical uses of the enclosure sense}

The mappings of the enclosure sense onto abstract or social domains give rise to a series of metaphorical patterns. The following ones are found in English:

1. The MIND CONTAINS THOUght, memories, knowledge, etc. The HEART may be a substitute of MIND when the trajector has an emotional value - Rhode Island is going to examine its Sunday sales law with possible revisions in mind (A05:24). 
2. BoOKS CONTAIN IDEAS. Here books is used as a generic term for writings, documents, literary works, newspapers, periodicals, journals, magazines, notes, the press, letters, compilations, papers, etc., or parts and sections of these. The trajector is the contents of the book - the professional dancer who related in a book how he parlayed his earnings into a \$2,000,000 profit on the stock market. (B13:91). The landmark may be referred to metonymically by the name of its author - the idea of death is more profound in Irenaeus than the idea of $\sin$ is (D04:57).

3. InSTITUTIONS CONTAIN PEOPLE and events. Organisations like political parties, police corps, societies and associations, councils, Congress, the clergy, the Church, Parliament, government, universities, schools, marriage, etc. illustrate this sense - explosion in the council. (A04:7), an office in the Socialist Party (A05:50).

4. Circumstantial states contain People. A series of difficult or bad conditions in which someone finds herself is considered as a container that reduces her mobility and exerts some control over her. On the contrary, a good situation implies access to otherwise hidden or inaccessible entities or things. This metaphor appears in expressions like in trouble, in need, in power, in office, in control, in command of, in a morass, in a controversy, in fellowship, in co-operation, in danger, in business, in a predicament, in privacy, in disgrace, in the wrong, in retirement, in possession of, in exile, in slavery, in circumstances, etc. - Republicans, if they had been in power, (A04:37), all children in need (A02:87)

5. CAUSES CONTAIN EFFECTS. An effect is hidden in the container in the sense that it is unknown, because the cause is previous to its effect-One advantage that would come to the city in having a full-time director, he said, is that East Providence would become eligible to apply (A05:12), Any harm in that? (P04: 86).

6. The Form CONTAIns the SUBSTANCE. According to this metaphor objects consist of two elements, a form and a substance, where the former, which is perceived, contains the latter, which is not perceived. - the content of faith is to be presented today in a form that can be understanded [sic] (D02:1), The governor's move into the so-called "blue law" controversy came in the form of a letter (A05:26).

7. ENTITIES CONTAIN QUALITIES. Qualities are conceived of as being inside objects, actions, events or activities - vigor in the performance, (C09:39), all the dash, color, flair and speed possible to encompass in a single boat (E06:35).

8. CONDUiT METAPHOR. Words and language in general are conceived of as containing meaning and ideas. Thus, meaning and ideas travel within language from speaker to hearer. This use appears in expressions with landmarks like word, report, resolution, speech, statement, sentence, terms, remark, message, etc. These refer to the language itself and not to the material 
support of that language; otherwise it would be a case of the BOOKS CONTAIN IDEAS metaphor - The Secretary of State himself, in his first speech, gave some idea of the tremendous march of events (A04:16), to compress in a sentence or two the complicated and prodigious contributions SAM RAYBURN has made. (H03:30).

9. PeOple CONTAin Behaviour (as air or gas), emotions (as fluids), qualities (as objects), and roles (as substance contained by the form) - The fumes of progress are in his nose (G08:55), fear in human beings (D07:42), the savage in man (C10:29).

10. Motivation CONTAins ACTION. Action is the consequence of a previously perceived motivation. The expressions in view of, in the interest of, in response to, in reply to, in sight of, etc. express this sense - ..reorganize city departments in the interest of efficiency and economy. (B07:20)

11. EVENTS CONTAIN PARTICIPANTS AND ACTIONS. Events are linguistically referred to as if containing other events, actions or participants - the final event in the Town Hall Festival of Music (C07:108), Both parties in the last election (A05:55).

12. Political entities contain People. A nation, province, county, etc. is considered as far as its administration or politics is concerned, and not geographically. Thus, it is a container for people, laws, social conditions, etc. within their scope of influence - in this republic no power to restrain him by force could exist (D05:3), Communist leaders in the provinces (B07:54)

13. ShAPE CONTAINS OBJECT. The shape of an object or person is conceived of as containing it. The landmark can be a noun that refers to a type of shape - $a$ cake in the shape of a fedora. (B05: 50), Your wife's in terrible shape (N01:102).

14. A CATEgORy CONTAins ITS MEMBERs. Classes, categories, and groups contain the elements within. - youngsters in this age group (C04:75), dogs in various other classes at the show (E05:5), ...how many Southerners there are in this category (G01:40).

15. Token contains Role. The role played by a person, action, or object is conceived of as contained by it - Some anti-organization Democrats saw in the program an opportunity to end the bitter internal fight within the Democratic party (A07:3).

16. Role CONTAINS TOKEN. The opposite relationship to the previous one holds here - an actress immersed in her role. (C02:35).

17. The Function CONTAins the ACTION - Hogan [...]lifted a hand in signal (N10:125). 
18. The ACtion CONTAINS THE FUnCtion. The expression no use/point in $V$-ing is an example of the use of this sense - Not that there's much use in locking up the smokehouse (L09:12).

19. A Picture CONTAINS A SitUATION. The elements in a picture are described as contained in the picture - ...is shown beginning in Fig. 7, page 65, and in the photos (E07:35).

20. THE SIZE CONTAINS THE OBJECT - ...an over/under double rifle for me in this caliber, using the now defunct Model 90 action in 20-gauge size (E10:16).

21. The Sight CONTAIns THE VIEW. The visual field of a living being contains the things seen - The car was now in sight (L04:71).

22. A MENTAL SPACE CONTAINS CONCEPTS AND ICMs. Mental spaces are packages of knowledge which are activated in the conversation in order to be used by speaker and hearer in the course of communication (Fauconnier \&Turner 1994). The unit in plays the role of what Fauconnier calls space-builder (Fauconnier 1985), since it introduces landmarks which constitute new mental spaces to be referred to in the conversation. This use is included in the metaphorical set, because mental spaces do not refer to physical space, but to abstract metaphorical space (a "package of knowledge"). If the landmark is a word that activates a domain of knowledge, then that mental space constitutes a ground for further reference. Using the unit IN, mental spaces can be construed with the container schema as, for instance, political systems Contradictions in Capitalism (K07:177) -, cultures - In most Western cultures (G05:70) -, imaginary worlds - these identical details of scene, action and word had occurred to him in a dream (F03:14) -, domains of human activity - the most telling cues in psychotherapy are acoustic (F01:31) -, games - a breaking table in blackjack (P06:124) -, literature - In American romance (F01:1) -, the media - this subject in <Eddies of the Day> (R06:110) -, tradition - IN TRADITION and in poetry, the marriage bed is a place of unity and harmony (F08:1) -, art, theatre, or cinema - you ought to be in movies! (R01:2) -, systems of measures - Dimensions in inches, and fractions of inches will give the displacement in cubic inches (E08:60) -, languages - the same remark to an Eskimo girl in Eskimo (F01:8) -, and finally, extralinguistic situations or pragmatic space, which indicates the speaker's attitude or approach to what is said - with expressions like in general, in principle, in particular, in fact, in effect, in the main, in all, in any case, in reality, in actuality, in point of fact.

23. A REFERENCE DOMAIN CONTAINS A CONCEPTUALISATION. In this case, the idea of reference point constructions is relevant (Langacker 1993). Langacker refers to "our capacity to invoke the conception of one entity as a cognitive reference point for purposes of establishing mental contact with another" (Langacker 1993: 1). In the case of the lexical unit in, the reference is made to a domain which serves as landmark within which a cognitive operation is 
performed. Expressions like in this regard, in this respect, in certain aspects, are conventionalised uses of this kind of reference. The construction adj. + in $+N$ implies that the quality expressed by the adjective is to be considered with the landmark domain as reference - rich in nutrients (E02:105), high in quality (F04: 106-107), light in color and fragrant in aroma (F04:53). Another type of construction takes as trajector nouns like difference, advantage, range, or verbs like excel, differ, which need a domain where the comparison is to be carried out - 16 male patients, ranging in age from 27 to 72 (E02:112).

\section{Specialisation of meaning}

One of the three semantic regions -topological, force-dynamic or functional- is highlighted in a process of partial sanction of the conceptual schema.

\subsection{Topological senses}

For these senses, the topological relation of coincidence between trajector and landmark is semantically prevalent over force-dynamic or functional aspects. Nevertheless, the latter remain in the background, and may produce distinctions that can be reflected in distinct senses of the lexical unit.

Sense 4: Inclusion. The trajector is found within the limits of an area or line. However, these limits are not conceptualised as an obstacle for it to leave that area or line. The control aspects are minimised. Force-dynamic aspects are not relevant either, as long as the trajector remains within the limits of that area or line. What is relevant here semantically is the loss of emphasis on the boundaries as an instrument of control, more than the two-dimensionality of the landmark. The fact that human abstract thought is able to abstract Euclidean dimensions, and consequently speak of containers as three-dimensional, areas as two-dimensional, and lines as one-dimensional, is just a metonymic abstraction of human thought. Natural meaning is more "physical". A focalisation on topological relations between trajector and landmark takes place, while control and force-dynamic images undergoes a bleaching process (see fig. $\mathrm{n}^{\circ} .3$ ).

This sense appears with landmarks like land, country, city, borough, suburb, park, territory, valley, forest, garden, continent, desert, island, peninsula, etc. - the need for unity in the country now (A04:39) -, or proper names that designate this type of geographical area - another setback in Berlin (A04:18). In general, landmarks denote areas which are conceptualised as having limits like ground, field, paths, roads, spots. Sometimes these limits are clear-cut, sometimes they are fuzzy. In any case, they mark the region where location of the trajector demands the lexical unit in to express the topological relationship of coincidence between both elements. 


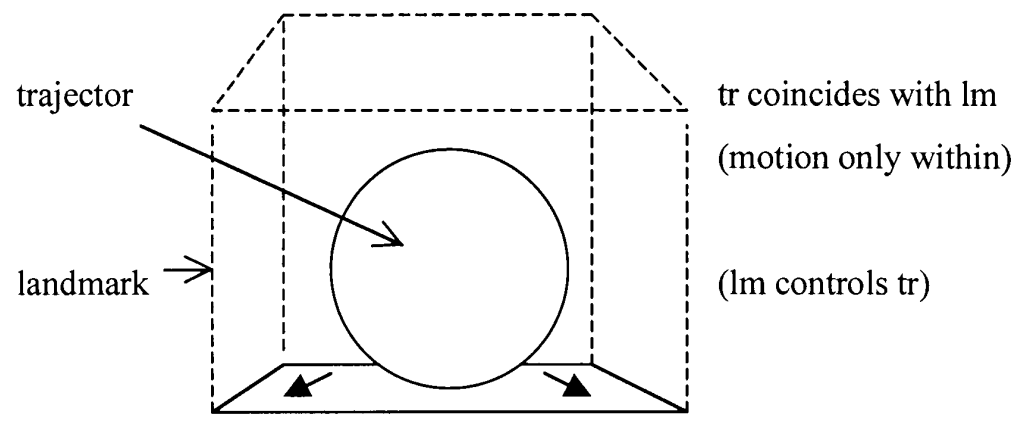

Figure $\mathbf{n}^{\mathbf{0}}$. 3. Topological inclusion. The boundaries on the bottom are highlighted.

Sense 5: Definite inclusion: With certain expressions like foreground, centre, middle, midst, dead, heart, rear, bottom, etc. and the points of the compass, the location of the trajector within an entity with limits is defined more closely than in sense 4 - atomic arms in the heart of this northernmost capital of the alliance (A04:10). This definition is given by certain landmarks that are a part of the whole area (see fig. 4).

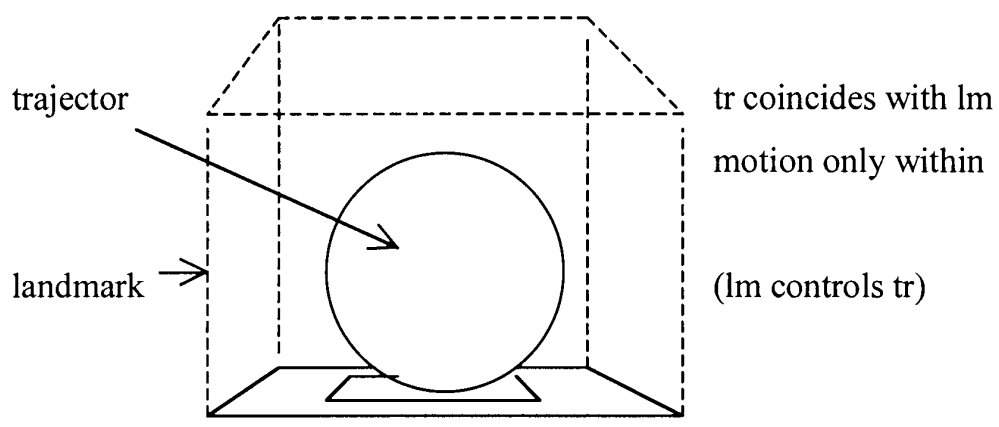

Figure $\mathbf{n}^{\mathbf{0}}$. 4. Definite topological inclusion. The inner area in the bottom represents the part where the trajector is located or included.

Sense 6: Medium: The term medium is understood as the intervening or surrounding substance, fluid, conditions or influences, i.e. the environment through which a force acts, an effect is produced, an object, living being, or another substance is preserved and exists (cf. Hawkins 1988). Whereas the idea of boundary is still present in senses 4 and 5, it is rather bleached out in this sense. What remains here is the relationship of coincidence in space of trajector and landmark. The landmark thus becomes the medium that fills out the interior region defined by the bleached boundaries. This sense occurs with landmarks like the air, the sky, heaven, space, the wind, woods, jungle, weather phenomena, acoustic environment, the weather, climate, 
chemical solutions, etc. - Their heads were in the air sniffing. (G04:3). Thus, the trajector is topologically perceived as coincident with the space filled by these media. Expressions like in the sun, in silence, in the open, in depth, in sunshine, reflect this sense (see fig. 5). The medium may also be fluids like water, soup, wine, snow, etc. or solid substances like mud, soil, sand, rice, sugar, chocolate, etc. - roots in the soil (C13:47). Certain collocations like in the distance, in the presence of, in the absence of, in evidence, illustrate conventionalised expressions of this sense - flashes in the distance (C08:31).

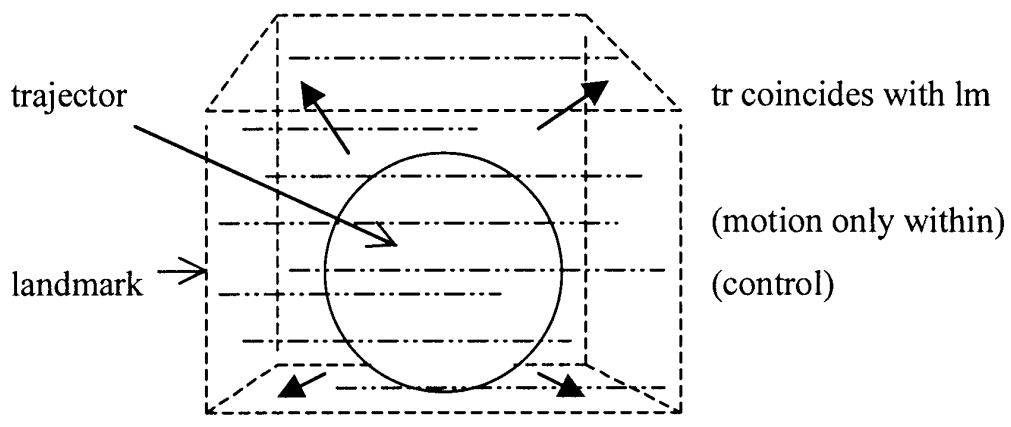

Figure $\mathbf{n}^{\mathbf{0}}$. 5. Medium. Semantic bleaching of boundaries

Sense 7: Massive medium. An entity is entirely or partly located in a massive chunk of material like a nail in a board, an ore in the rock, etc. (see fig. 7). a tap in the wall (E13:63), a nail in the wall (N01:142).

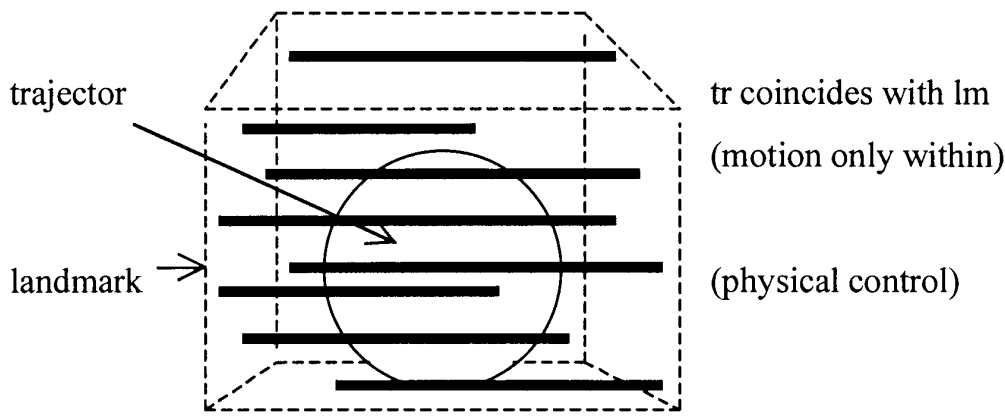

Figure $\mathbf{n}^{\mathbf{0}}$. 6. Massive Medium. Bold lines represent the MEDIUM as a solid body.

Sense 8: Material. Entities that are made of a material are spoken of as if included in a medium filled with that material. Colours are conceptualised as materials in this 
sense. So, we can find a statue in marble, a coin in gold, etc. - Arabic lettering in gold (E13:62), an antique French chess set in ivory and sandalwood (R09:16)

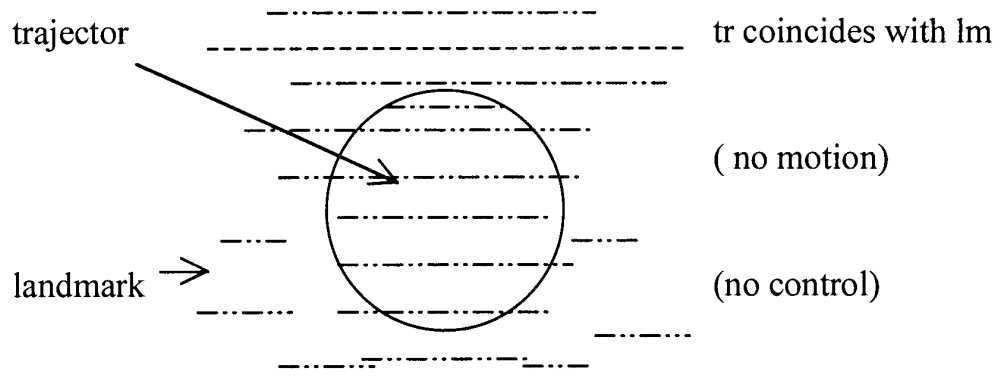

Figure $\mathbf{n}^{\mathbf{0}}$. 7. Material. The boundaries are bleached out of the conceptualisation.

Sense 9: Integrated parts are in the whole. Parts of wholes, like elements in a system, are perceived as integrated parts, not as attached or added parts, and are conceived of as in the interior region defined by the external boundaries of the whole (see fig. 8). Senses 9 and 10 are within the topological region, but they are proximal to the control region, since there is a feeling that the global entity holds certain control over its parts. The landmarks may be programmes, sets, collections, series, machines, or other types of complex entities - the indispensable elements in a sound health program (A03:78), the other constituents in a built detergent (J05:56).

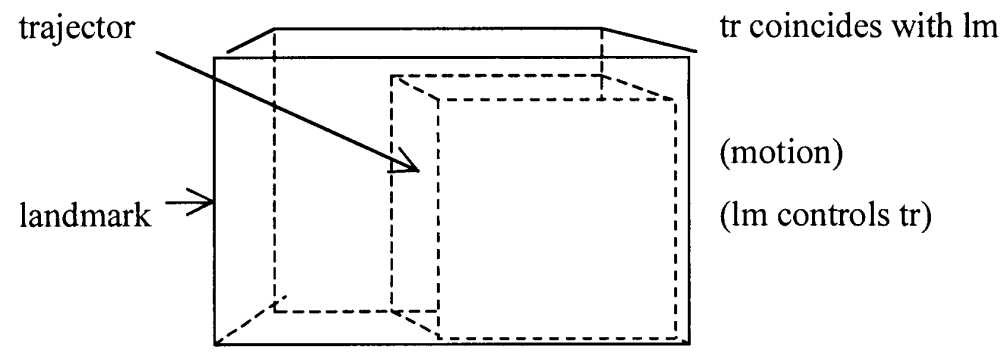

Figure $\mathbf{n}^{\mathbf{0}}$. 8. Integrated part. The relevance of the boundaries recalls the relation of control.

Sense 10: Lack of a part is a part itself. This sense is a shift of the previous one. An interruption in a whole is seen as a part of the whole (see fig. 9). For example $a$ crack in the wall, a hole in a box, lack in personnel, vacancies in a hotel, openings, 
notches, defects, etc. - a gate in the wall (E13:61), a picture window in the abdomen (C05:45), The City Purchasing Department [...] is lacking in experienced clerical personnel (A01:9).

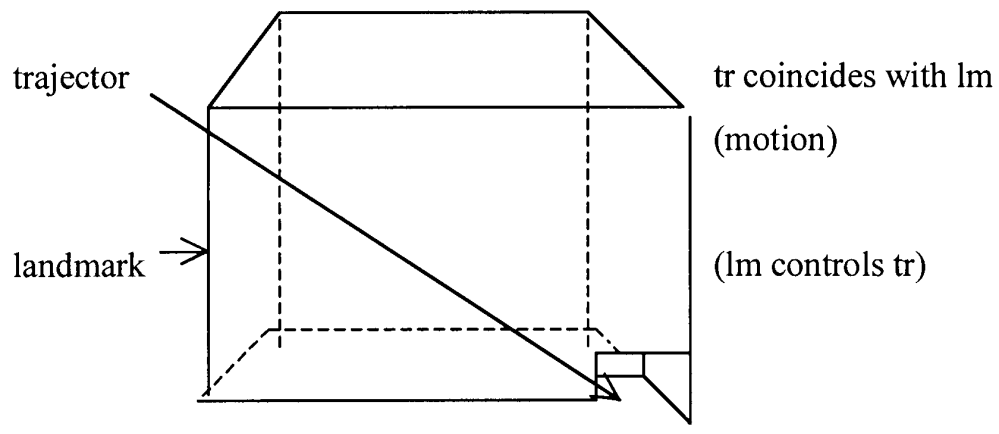

Figure $\mathbf{n}^{\mathbf{0}}$. 9. Lack of part is a part

Metaphorical uses of the topological senses:

Sense 4 (inclusion) is mapped onto other domains in the following metaphors:

- KNOWLEDGE is a LAND. We use this metaphor when we speak of areas or fields of knowledge - a master's degree in physics, chemistry, math or English (A02:68), research in medicine (A03:77).

- PUBLIC LIFE is a LAND divided into fields, areas, etc.- reforms in military and economic aid policies in the critical areas (A04:32).

- THE TIME METAPHOR. In is used in a temporal sense to indicate that some event, entity, action, state, etc. coincides with a span of time which is included in a larger span. If time is seen as a path according to the TIME METAPHOR, then the smaller span is a piece of the larger segment of time. Therefore, the lexical unit in is used with temporal complements referring to periods which include at least three smaller periods, namely the small period we refer to with the trajector, one period before the start of it, and another period after the end of it. Usual expressions with temporal in are those that denote periods which may be conceived of as including the three subperiods described, like weeks, days, months, years, seasons of the year, parts of the day, periods of human life like childhood, life itself as a period, hours, minutes, seconds (in hyperbolic use), etc. and idiomatic expressions like in time, in due time, once in a while, in the meantime, in advance - in the future such topics as Angola will be discussed in advance (A04:8).

A special use of the time metaphor takes into account only two of the three possible periods included in the landmark. The period occupied by the trajector 
coincides in this case with the end of the period denoted by the landmark (see fig. 10) - I was back in ten minutes (L02:6).

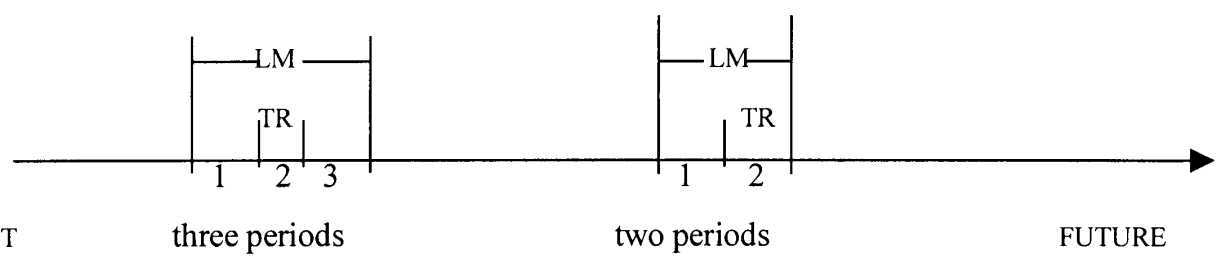

Figure $\mathbf{n}^{\mathbf{0}}$. 10. Periods included in temporal landmarks with in.

Sense 6 (MEDIUM) is projected according to the following metaphors:

- LIGHT is a FLUID. Light is conceived of as a fluid medium where other entities are located, for example in the light, shadow, daylight, dawn, moonlight, darkness, etc. - an August afternoon in the shade of the curbside trees (G14:50)

- A GROUP OF PEOPLE is a MASS. This metaphor occurs with landmarks like audience, crowd, assembly, army, community, population, public, etc. - In the audience a man named Ferguson (K05:165), Some can be lonely in a crowd (M04:24).

- INTERPERSONAL CONDITIONS are WEATHER CONDITIONS. The relationships between people take place in an emotional medium, expressed with landmarks like climate, atmosphere, etc. - the ministers have met in a climate of candor (A04:3).

- An Emotion is a Medium. People are conceived of as immersed in emotional states like in love, in ecstasy, in awe, in amazement, in merriment, in panic, in a thrill, in fear, in desperation, in hope, in a fit of anger, in horror, in dismay, in pleasure, in surprise, in enthusiasm, in sympathy, in pain - In the fevered, intoxicating, breathless state of being in love (B08:79), he yet stared in fascinated horror (K02:97).

- An Individual state is a Medium. People are immersed in different kinds of states, which are not necessarily emotional. This is seen in expressions like in an attempt to, in an effort, in a mood, in slumber, in mercy, in a rush, in earnest, in faith, in disobedience, in sin, in disbelief, in a spirit, in disagreement, in sleep, in error, in expectation, in laughter, in an endeavour, in consciousness, in a trance, in a (good/bad) condition, in ignorance, in a hurry, in agreement, in wisdom, in blame, etc. - while his colleagues [...] were shaking their heads in disagreement (B05:64), O Blessed Virgin Mary, [...] look down in mercy upon England (D03:46)

Plants or animals may also be immersed in individual states - a good sloe tree, or perhaps some nice pussy willow in bloom (J10:8), female dogs in heat (P01:6). 
- A Quality is a MEDIUM. Objects or living beings are conceptualised as immersed in their qualities - In the fullness of her vocal splendor, however, she could sing the famous scene magnificently (C02:39), The garden below was lacy with dew and enchanting in its small wildness (P04:30).

- An Activity is a MEDIUM where people are immersed - many of the Doctor Frauds using these false health gadgets are still in business (F10:45).

- Social LIFE is a MEDIUM. People are seen as immersed in social life - She had been moving in cafe society as Lady Diana Harrington (F09:11).

Sense 9 (integrated part) is extended by means of the following metaphors:

- NUMBERS are part of BIGGER NUMBERS - one person in a hundred. (A05:16).

- SCAlE METAPHOR. For example in the expressions in excess, in large part, in large degree, in order to, in addition to, in the range of, in low concentration, etc. the trajector is conceived of as located in some place within a scale $-a$ valuation for this property in excess of two million dollars (B15:11), temperatures in the range of 180 and above (J06:1).

- CONCEPTS are PART OF COMPLEX CONCEPTS. Certain concepts are understood as a compound of several simpler concepts (for example, a budget implies a purpose, time, money, etc.) - the 540 million dollars in the 1961-62 budget (A03:77), The concept of unity, in which positive and negative are attributes of the same force, in which good and evil are relative (D01:55).

- ACTIONS and PARTICIPANTS are PART OF more complex ACTIONS - How effective have Kennedy administration first foreign policy decisions been in dealing with Communist aggression? (A04:33).

- A GROUP is A WHOLE and its members are parts of it. For example, members of a family, the staff of a company, the cast of a play, an orchestra, etc. - you are in God's family (D06:42).

\subsection{Force-dynamic configuration senses}

Specialisation of meaning proceeds by means of partial sanction of one of the three semantic configurations of the conceptual schema. If the force dynamic configuration of the participants in the situation is profiled, the interaction axis between trajector and landmark is highlighted as the most relevant aspect of the relation. Other semantic regions like the topological relation of coincidence and the functional orientation remain in the background. In is compatible in context with other linguistic units that express motion along a path ending in the interior of a landmark. Further senses are derived from the central force-dynamic sense when the background attributes reappear, or certain elements of the gestalt are highlighted (shifts).

Sense 11: Movement from the outside. The trajector defines a path towards the interior region defined by a container, or towards the space filled out by a medium, or 
towards the interior defined by the limits of an area (see fig. 11). The trajectory ends up in the interior of the landmark.

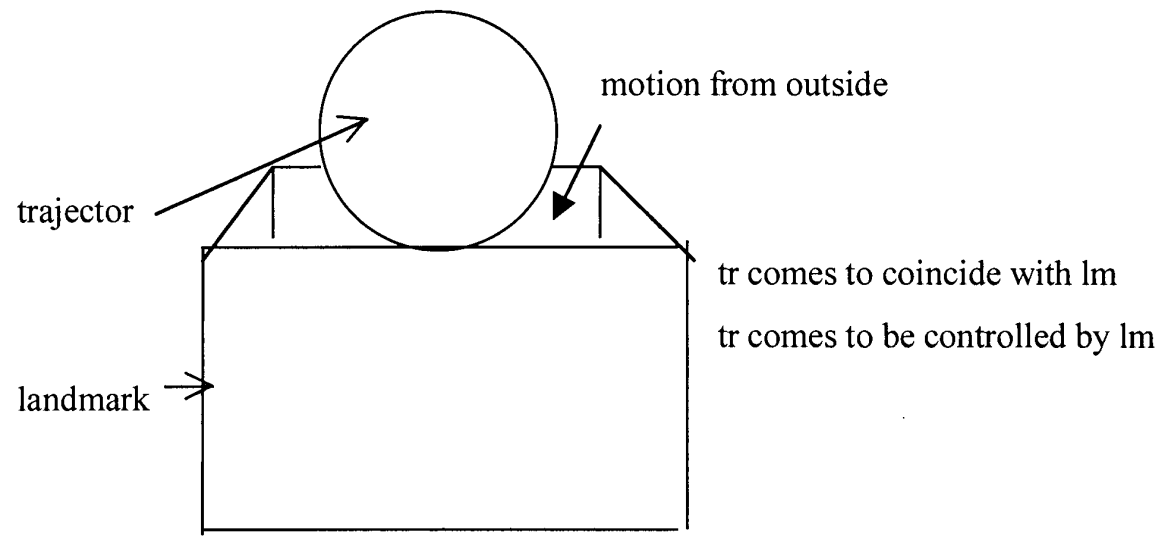

Figure $\mathbf{n}^{\mathbf{0}}$. 11. Motion into container, MEDIUM, or area.

This sense occurs in context with verbs of movement like place, put, set, introduce, confine, shut, lock, fall, hide, etc. Verbs like merge, sink, dive, plunge, immerse are also possible when the movement ends in a medium. The verb indicates the manner of the movement and the unit in indicates the direction of that movement in relation to the interior region of a landmark - put the money in an envelope (L08:100) (into container), the youngsters were told to express their fears, to get them out in the open (D07:3) (into MEDIUM).

Sense 12: The trajector becomes an integrated part of the landmark. In this case, the motion ends in a fusion of trajector and landmark (see fig. 12). Verbs like insert, install, implant, incorporate, fit in, take in, include, carve in occur with this sense - a deadline for the parties to join in a national coalition government (A09:91), if you can't put garlic in it, put chocolate in it (R02:94).

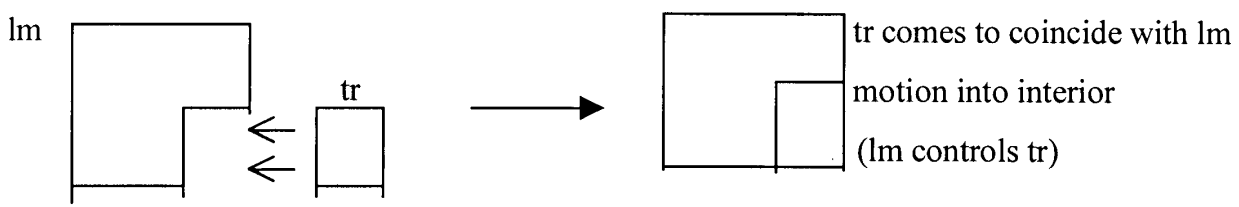

Figure $\mathbf{n}^{\mathbf{0}}$. 12. Trajector becomes an integrated part of landmark

Sense 13: Movement of integrated parts. Integrated parts of the landmark move producing some effect. The result is a change in the nature of the landmark (see fig. 13). This happens with expressions like increase, raise, reduction, gain, upturn, 
improvement, rise, cut, diminish, falling off, growth, diminution, upsurge, revolution, etc. followed by in - changes in the structure or composition of the lunar surface material. (J01:20), a slow diminution in size (J07:4 ), a five per cent growth in the gross national product (A05:55).

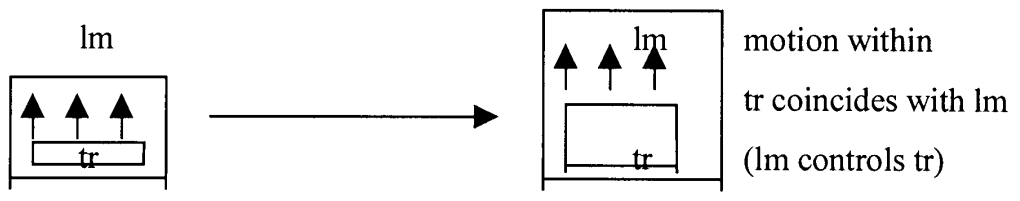

Figure $\mathbf{n}^{\mathbf{0}}$. 13. Movement of integrated parts

Sense 14: Imaginary motion into a part of trajector. The speaker performs a scanning of the trajector, so that perception moves from one part of the trajector to another (see fig. 14). The latter part constitutes the landmark of the expression. This sense occurs with expressions of the type end in (A pencil ending in a sharp point), culminate in, etc. - Christ [...] whose work culminates in the achievement of immortality (D04:60)

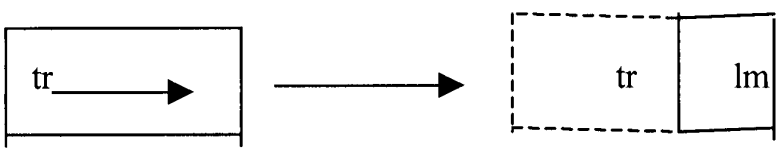

tr comes to coincide

with $\operatorname{lm}$

Figure $\mathbf{n}^{\mathbf{0}}$. 14. Imaginary motion into a part of trajector

Sense 15: Motion attempting to cross the boundary into the interior region of a container or to come into a massive medium (see fig. 15). This sense often describes violent movements of objects that crash against the surface of other objects. However, the interior region is not reached - Pressing his cigarette out in the earth (K02:25), Roberts' full weight struck him at that moment in the groin (L06:7), A painful stab hit him in the abdomen (M06:23).

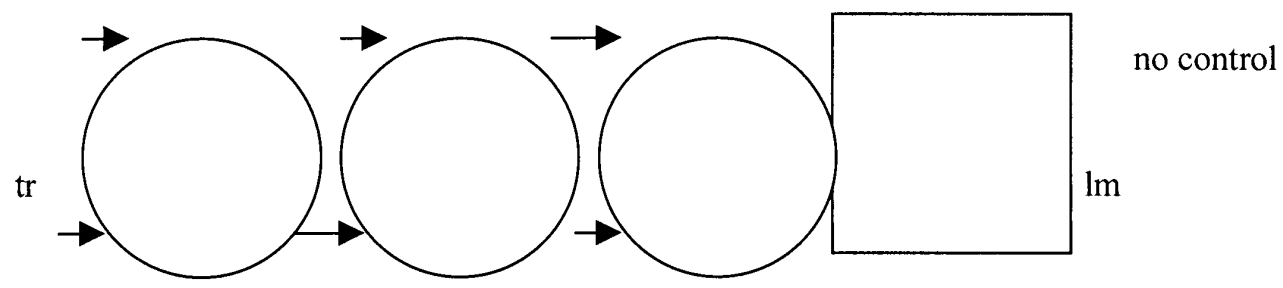

Figure $\mathbf{n}^{\mathbf{0}}$. 15. Attempt to reach interior

Sense 16: Trajector becomes a group. The movement of the trajector consists of becoming a plurality of entities with in a group - he tore the envelope in pieces (P03:46). 
The most usual metaphorical uses of the force-dynamic senses are the following: Mappings from sense 11 (motion into container, MEDIUM or area:

- SEEING is ENTERING. With verbs like look, stare, etc. and complements like the eyes, the face, etc., to denote that the person who looks wants to go into the other person's feelings, thoughts, etc., or with other objects to denote searching in the interior - Mike crawled to the door and peered in [the room] (N03:144).

- InTENTIONAL STATES are MovemENTS. This metaphor interprets people's intentional states as movements towards an aim, target, or the final point of the state, which are seen as an interior region of another entity. It occurs in expressions like interest in, confidence in, be in favour of, believe in, have faith in, engage in, acquiesce in, trust in, be involved in, confide in, concern in, indulge in, in support of, etc. - When that fear has been removed by faith in Jesus Christ (D07:101), The United States [...] is mainly interested in setting up an international inspection system (A04:25).

- Purposes are Destinations. According to the Event Structure Metaphor (Lakoff 1993), purposes of action are seen as destinations at the end of a path. In this case, the path ends in an interior region defined by a container or a medium. This metaphor occurs in expressions like in + present participle, step in, do something in favour of, succeed in, grant-in-aid, lead in, to have a point in, progress in, help in, aid in, etc. - the first step in obtaining a home rule charter for the town (A05:59), the little plane was its sole replacement in carrying the United States mails (F05:9).

- ACTIONS are SELF-PROPELLED MOVEMENTS: An action or activity is conceived of as a movement that follows a path towards an object. It occurs in expressions like intervene in, specialise in, experiment in, assist in, participate in, invest in, train in, instruct in, cooperate in, etc. - Parker should not be encouraged nor assisted in diffusing his opinions (D05:4), the city also intervened in the Hughes bankruptcy case (A09:16).

- RESUlts are DESTINATIONS. With expressions like result in, end in, etc. - It sometimes ended in death-like trances (K04:26), programing and budgeting completely beyond the capabilities of the recipient country would result in the frustration of the basic objective of our development assistance (H02:13).

- The EAR is a CONTAINER for speech sounds. This metaphor occurs with verbs like speak, murmur, whisper, shout, etc. followed by the expression in the ear - Manuel whispered in the ears of the Sioux that the Cheyennes were comin' to raid 'em for their horses (N04:29)

Mappings from sense 15 (attempt to reach interior)

- ACTIONS are PIERCING MOVEMENTS. This sense occurs when gestures are intended to affect the feelings or the behaviour of another person. Verbs like laugh, shut the door, slam the door, shake one's fist, generally followed by the lexical unit in and a noun referring to human beings, or by the expression in someone's face - the bandit laughs in his face (K08:5). 


\subsection{Functional configuration senses}

In the conceptual schema, function may be profiled. The relation of control exerted by the landmark is highlighted. The force-dynamic and topological relationships remain in the background. These can provide an element for contrast with other lexical units that might occur in the same contexts as in, i.e. where functional relationships between the participants are focused on semantically.

Sense 17: Control. Partial sanction of the conceptual schema may produce a focalisation on its control configuration. In this case, motion or action of the trajector is controlled in a particular way by the action of the landmark, by its presence, or by its mere existence (see fig. 16)

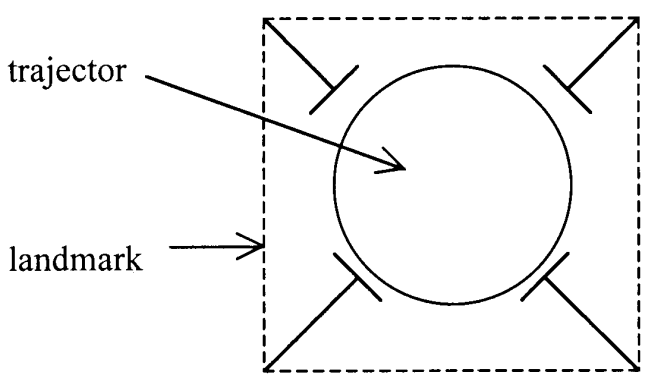

$1 m$ controls tr

tr coincides with interior of $1 \mathrm{~m}$

(motion within interior)

Figure $\mathbf{n}^{\mathbf{0}}$. 16. Landmark controls trajector. Protection or reclusion.

The closest control instruments to human beings are their hands and arms. Thus expressions like in hand, hand in hand, in the hold of, in someone's hands, in someone's arms, in someone's control, in the grip of, are the most salient expressions of this sense. Others imply some control by means of another instrument like in harness, in handcuffs, in the stirrup, etc. -A man with a baby in his arms (D07:61), Philip Spencer, in handcuffs and ankle irons (P07:117).

Sense 18: Path controls movement. Partial sanction may put emphasis on two of the conceptual configurations. When both control and motion are stressed, a sense appears which can be located between the conceptual regions of control and motion. In this case, the trajector is moving along a path and the trajectory of that path defines the movement (see fig. 17). This is linguistically expressed with the lexical unit in followed by nouns that denote types of trajectory: in a line, in a move, in a motion, in progress, in the search for, in an ellipse, in an orbit, in a direction, in due course, in progression, in a sequence, in the wake of, in succession, in circulation, in the course of, etc. - It moved in a silver arc (L06:41), an impetus in three main directions (A04:20). 


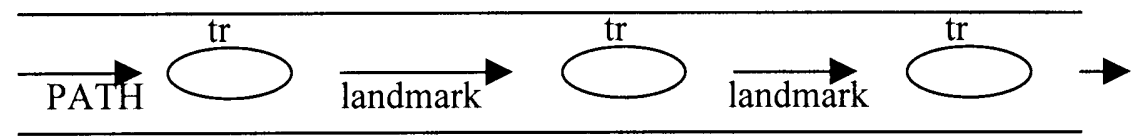

Figure $\mathbf{n}^{\mathbf{0}}$. 17. Path controls movement. The arrows stand for the direction of the movement.

Metaphorical uses of functional senses

- MANNER controls ACTION. This occurs in expressions like, in a manner, in a style, in a sense, in force, in particular, in a tempo, in a mood, in a fashion, in a way, in one's stride, where manners, ways, etc. guide, lead, or control action - the way in which he has turned his back on his 1910 philosophy (A05:57), the exact manner in which the vote is handled (A05:64).

- INSTITUTION controls PEOPLE: Institutions exert some control over the people who belong to them, work for them or have any relationship with them. Expressions like in prison, in the army, in school, in hospital, in court, etc. illustrate this pattern - a penalty of one to five years in prison (A02:39), It hadn't been this way in college, or in nurses' training; it wasn't this way in the hospital at San Diego (P05:55).

- SITUATION controls PEOPLE: In certain states or situations, people, animals, or plants are under other people's supervision or control, like in quarantine, in custody, in care, in secret, in observation, etc. - a school with children living full time in its care must take full responsibility for their welfare (F04:9), While he was in custody his wife divorced him (F08:38).

- POSITION controls TRAJECTOR. This sense appears in expressions that provide a kind of position or situation as a landmark. This landmark determines the potential of action or movement of the trajector. It occurs in expressions like in opposition, in touch, in a position, in a situation, in contact, in combination, in conjunction, in relation with/to, in equilibrium, in comparison, in proportion to, in contrast, in contradiction, in analogy, in connection, in turn, etc. - a foreign government, political party or personality in opposition or preference to the American system (B04:81), In such conditions all freedoms are lost (B07:42).

\section{A radial category for in}

The senses of the radial category for the lexical unit in have been illustrated in the previous sections. The primigenial sense (sense 1) combines the three modes of spatial configuration: topology, force-dynamics, and function. The conceptual image-schema combines, therefore, topological inclusion with a relation of control of the trajector by the landmark, as well as a kinetic axis characterised as not exiting the interior region of the landmark. This sense is called here enclosure, and responds to the basic logic of the container image-schema (Lakoff and Johnson 1981; Lakoff 1987; Fornés y Ruiz de 
Mendoza 1996). The conceptual image-schema undergoes two shifts: partial enclosure and interior is landmark. Partial enclosure implies the loss of some of the boundaries that define the container, so that the control of the landmark over the trajector is reduced. At the same time the protective aspects of the control prime over the isolation of the trajector. Interior is landmark implies an even weaker role of the boundaries and only the space defined as an interior region is emphasised. These two shifts produce two chains of senses within the conceptual region of the topological configuration. In the partial enclosure chain, boundaries are relevant to a certain extent. In the interior is landmark chain, the interior region is more relevant than the boundaries. Both chains give origin to a prototype each. The chain where the boundaries are relevant produces a main sense called inclusion. In this case the boundaries of a volume lose profile in favour of the limits of the covered area. That area functions as a landmark. When a part of this area is made explicit we get a new sense called definite inclusion. The chain goes on to give emphasis to parts of wholes. Finally, the lack of a part in the whole is also expressed by a new sense. The second chain produces a prototype called medium, where the interior region of a container is conceptualised as filled out by some matter. At the same time boundaries are no longer an active part of the conceptualisation. The trajector is conceived as immersed in the medium. Trajectors are easily conceptualised as immersed in gaseous or liquid media. This conceptualisation changes when the medium is a substance like sugar, rice, etc. In this case, the trajector is covered with it, but not completely immersed in it. A sense called massive medium stands for a conceptualisation where the trajector is in a massive chunk of matter, completely or in part. A new sense is posited for that conceptualisation where an object is made out of some material, as if it were immersed in a medium of that material.

The conceptual schema gives rise to two chains where the force-dynamic configuration is the most relevant factor in the conceptualisation. In one of them, movements within the landmark are conceptualised as movement of integrated parts, or as imaginary motion or scanning of internal parts. The other chain represents conceptualisations where trajectors come from the external space into the interior region defined by the boundaries of the landmark. Motion from outside is the central sense here. Two senses emerge from this one. One of them implies that the trajector becomes an integrated part of the landmark. This sense is found in the intersection of the topological and the force-dynamic conceptual regions. Partial sanction of the motion from outside sense leads to the farthest sense in the chain, called attempt to reach interior, where the final stage of the movement is not accomplished, i.e. the interior region is not reached.

Finally, partial sanction of the conceptual schema focuses on control of the landmark over the trajector. Partial sanction may also focus on control and movement at the same time, producing a further sense, where the landmark is conceived of as a path that controls movement.

Conceptual regions represent different modes of physical experience. In Figure $\mathrm{n}^{\circ}$. 18, the central triangle represents conceptualisations of primigenial physical experience with containers, and gives rise to the conceptual schema. Distance between labels roughly stands for conceptual distance between senses.

At the same time, the closer a chain approaches the adjacent conceptual region, the stronger the influence of that region in the conceptualisation. The senses represented 
in the radial category are not clear-cut categories, but they should be seen as merging into each other. The analysis of a large number of examples provides evidence that many instances cannot be clearly identified with one single sense. On the contrary, they show semantic aspects that could be assigned to two closely related senses.

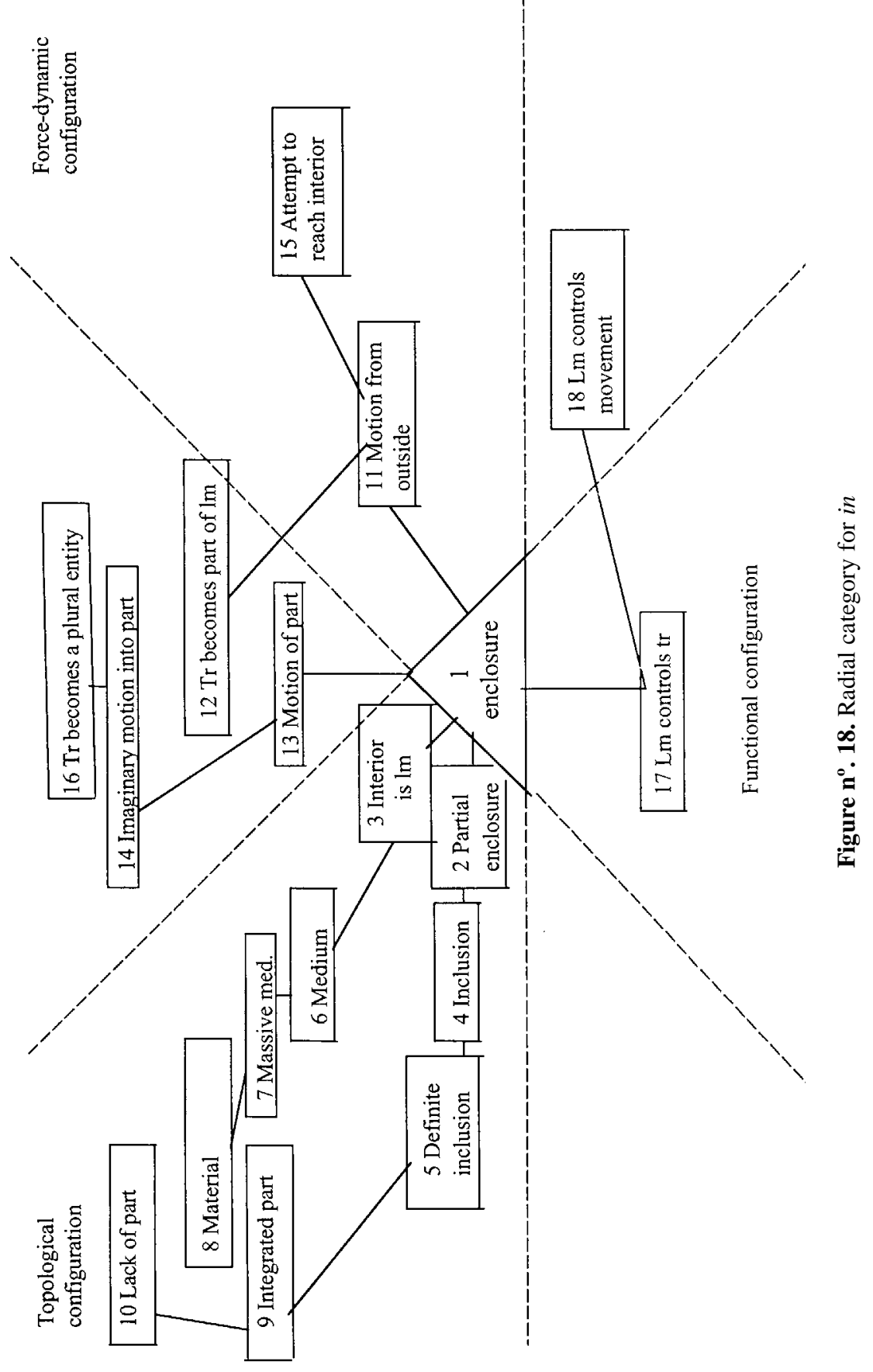




\section{Conclusions}

The polysemy of the lexical unit in turns out to be a quite complex integrated system. The former controversy on the nature of the landmark as a container or a medium might be superseded by a conception with more than one prototype. After an analysis of a large number of examples it turns out that the lexical unit in gives predominance to a topological configuration in the conceptualisation of the relationship between trajector and landmark. Apart from the conceptual image-schema (enclosure), which is based on the container schema, two further prototypes can be posited, and both have the topological configuration as the most relevant one. The senses inclusion and medium constitute the prototypes that give origin to two further chains of senses. The three-dimensionality of the landmark is not considered as a relevant semantic feature for the description of the semantic category. On the contrary landmarks of in can be conceived of as three-, two- or one-dimensional.

The enclosure prototype subsumes the three semantic modes of the spatial conceptualisation of in: the trajector coincides with the interior region defined by the landmark; the trajector can move within that interior region, and finally, the landmark exerts control over the trajector, either offering it protection by preventing access of external entities to it, or maintaining it in isolation by preventing its access to the exterior.

The medium and the inclusion prototypes both put an emphasis on topological coincidence of the trajector with the interior region defined by the landmark. The former puts the emphasis on the interior region itself, whereas the latter puts the emphasis on the boundaries. In neither of them are the control and force-dynamic aspects profiled.

This paper offers two types of conclusions. On the one hand, it corroborates the continuum hypothesis between lexicon and grammar. It has been shown that the syntactic category of in, as of most of prepositions, is not clear-cut, and that there is a continuum between lexical and grammatical uses.

On the other hand this paper represents a step forward in semantic description. As far as theoretical modelling is concerned, the radial network model of polysemy has been improved. Conceptual distance between senses is graphically represented. Directions in semantic specialisation are shown by conceptual regions. These conceptual regions are defined by three types of spatial configuration: topological, force-dynamic, and functional. This model integrates previous descriptions that used only one of these three parameters in isolation, and ignored the others. Moreover, it provides a systematic model for the polysemous semantic structure of lexical units that express spatial or temporal relations in English. The centre of the network is a conceptual schema based on bodily experience. The combination of the three experiential modes (function, force-dynamic interaction and topology) results in the conceptual schema. Specialisation of meaning is explained by means of conceptual shifts as well as by diverse types of partial sanction of the conceptual schema. The results are chains of senses in the three configurational conceptual regions. 
Specialisation of meaning is claimed to be language specific, and determines conceptualisation of space in adults. Metaphorical uses of in express relationships in domains other than the spatial domain. These uses can be accounted for by means of mappings according to Lakoff's (1993) metaphor theory. Though the cognitive principles are universal, the particular patterns of metaphorical semantic extension are claimed to be culture specific. The radial network proposed is more powerful than previous radial network models. This study cannot be assumed to be exhaustive, because particular usages might be absent from the corpus used. Nevertheless, frequency of a particular sense may be an indication of its prototypical character for the category.

A synchronic study like the one carried out in this paper can never give a complete account of grammaticisation and lexicalisation patterns. Therefore, a diachronic study of semantic structure, both from an ontogenetic as well as from a philogenetic perspective of the history of language, would be complementary to this work. Psycholinguistic research in first language acquisition would provide evidence of actual semantic extension from preconceptual elements through conceptual imageschemas up to metaphorical and abstract domains. The model could also be tested in the foreign language class for teaching semantics of spatial relationships. Furthermore, psycholinguistic experimentation in second and foreign language learning would test the ontogenetic patterns of polysemy development.

\section{References.}

Bennett, D. C. 1975 Spatial and Temporal Uses of English Prepositions: An Essay in Stratificational Semantics, London: Longman.

Boers, F. 1996 Spatial Prepositions and Metaphor: A Cognitive Semantic Journey along the Up-Down and the Front-Back Dimensions. Tübingen: Gunter Narr Verlag.

Brugman, C. M. 1980 Story of OVER, University of California at Berkeley, M. A. thesis.

Chomsky, N. 1965 Aspects of the Theory of Syntax, Cambridge, Mass.: MIT Press.

CIENKI, A. J. 1989 Spatial Cognition and the Semantics of Prepositions in English, Polish and Russian, München: Verlag Otto Sagner.

Cuyckens, H. 1988 'Spatial Prepositions in Cognitive Semantics' in Hüllen,W. \& R. Schulze (eds.) Understanding the Lexicon: Meaning, Sense and World Knowledge in Lexical Semantics, Tübingen: Max Niemeyer Verlag, 316-328.

------1993 'The Dutch Spatial Preposition "in": a Cognitive-semantic Analysis', in Zelinsky-Wibbelt, C. (ed.) The Semantics of Prepositions, Berlin: Mouton de Gruyter, 22-72.

-----1994 'Family Resemblance in the Dutch Spatial Preposition op', in Schwarz, M. (ed.) Kognitive Semantik, Tübingen: Gunter Narr, 179-195. 
1995 'Family Resemblance in the Dutch Spatial Preposition door and langs', in Cognitive Linguistics, 6, 2/3, 183-207.

Deane, P. D. 1993 'At, by, to , and past: An Essay in Multimodal Image Theory', Proceedings of the Annual Meeting of the Berkeley Linguistics Society, 19, 112124.

Dewell, R. B. 1994 'Over Again: Image-schema Transformations in Semantic Analysis', Cognitive Linguistics, 5-4, 351-380.

Dirven, R. 1981 'Spatial Relations in English', in Radden, G. \& R. Dirven (eds.) Kasusgrammatik und Fremdsprachendidaktik, Trier: WVT Wissenschaftlicher Verlag, pp103-131.

-----1989 'Space Prepositions', in Dirven, R. \& R. A. Geiger, (eds.): A User's Grammar of English: Word, Sentence, Text, Interaction. Frankfurt am Main: Peter Lang Verlag, 519-550.

-----1993 'Dividing up Physical and Mental Space into Conceptual Categories by means of English Prepositions', in Zelinsky-WibBelt (ed.) The Semantics of Prepositions, Berlin: Mouton de Gruyter, 73-98.

Fauconnier, G. 1985 Mental Spaces: Aspects of Meaning Construction in Natural Language, Cambridge, Mass.: MIT Press.

Fauconnier, G. \& E. Sweetser (eds.) 1996 Spaces, Worlds, and Grammar, Chicago: The University of Chicago Press.

Fauconnier, G. \& M. Turner 1994 Conceptual Projection and Middle Spaces', Report 9401, Department of Cognitive Science, UCSD.

FornÉs, M. \& F. J. RuIZ DE MENDOZA 1996 'Esquemas de imágenes y construcción del espacio', RILCE, Universidad de Navarra,

FrancIS, W. N. \& H. KuCERA 1961 A Standard Corpus of Present-Day Edited American English, Providence, Rhode Island: Brown University.

Givon, T. 1993 English Grammar: A Function-Based Introduction, Amsterdam: John Benjamins.

Hawkins, B. W. 1984 The Semantics of English Spatial Prepositions, University of California San Diego, PhD. Dissertation.

-----1988 'The Category Medium', in Rudzka-Ostyn, B. (ed.) Topics in Cognitive Grammar, Amsterdam: John Benjamins, 231-270.

Herskovits, A. 1986 Language and Spatial Cognition: An Interdisciplinary Study of the Prepositions in English, Cambridge: Cambridge University Press.

Hottenroth, P. M. 1993 'Prepositions and object concepts: A contribution to cognitive semantics' in Zelinsky-Wibbelt, C. (ed.) The Semantics of Prepositions, Berlin/New York: Mouton de Gruyter, 179-220

Johnson, M. 1987 The Body in the Mind, Chicago: University of Chicago Press. (Sp. Transl. 1991 El cuerpo en la mente. Madrid: Debate).

LAKoff, G. 1987 Women, Fire, and Dangerous Things, Chicago: University of Chicago Press. 
LAKofF, G. \& M. Johnson, 1980 Metaphors We Live By, Chicago: University of Chicago Press. (Sp. transl.: 1991 Metáforas de la Vida Cotidiana, Madrid: Cátedra.)

1999 Philosophy in the Flesh: the embodied mind and its challenge to western thought, New York: Basic Books.

LANGACKer, R. W. 1987 Foundations of Cognitive Grammar. Volume I: Theoretical Prerequisites, Stanford: Stanford University Press.

-----1991a Foundations of Cognitive Grammar. VolumeII, Stanford: Stanford University Press.

1991b, Concept, Image, and Symbol, Berlin: Mouton de Gruyter.

1993 'Reference-point Constructions' Cognitive Linguistics, 4-1, 1-38.

LEECH, G. N. 1969 Towards a Semantic Description of English, London: Longman.

LINDKVIST, K. G. 1950 Studies on the Local Sense of the Prepositions IN, AT, ON, and TO in Modern English, Lund: Berlingska Boktryckeriet.

-----1976 A Comprehensive Study of Conceptions of Locality in which English Prepositions Occur, Stockholm: Almqvist \& Wiksell International.

Lindner, S. J. 1983 A Lexico-Semantic Analysis of English Verb Particle Constructions with 'Out' and $U p^{\prime}$ ', Bloomington, Indiana: Indiana University Linguistics Club.

Miller, G. \& Ph. N. Johnson-Laird 1976 Language and Perception, Cambridge: CUP

NAVARro i FERrANDO, I. 1998 "A multimodal system for the description of spatial semantics: the preposition on.”, in José Luis Cifuentes Honrubia (ed.), Estudios de Lingüística Cognitiva, Alicante: Universidad de Alicante, 767-788.

------to appear "Towards a description of the semantics of AT", in Hubert Cuyckens and Günter Radden (Eds.), Perspectives on Prepositions Tübingen: Niemeyer Verlag.

PEÑA, S. 1997, 'The Container Image-schema and Other Subsidiary Image-schemata', in Actas del XXI Congreso AEDEAN, Universidad de Sevilla.

QUIRK et al., 1985 A Comprehensive Grammar of the English Language, London: Longman.

RADDEN, G. 1981 'Die übertragenen Bedeutungen der englischen Raumpräpositionen', in Radden, G \& Dirven, R. (eds.) Kasusgrammatik und Fremdsprachendidaktik, Trier: WVT Wissentschaftlichen Verlag, 133-179.

-----1989 Figurative Use of Prepositions, in R.Dirven \& R. A. Geiger (eds.) A User's Grammar of English: Word, Sentence, Text, Interaction. Frankfurt am Main: Peter Lang Verlag, 551-576.

Rice, S. 1996 'Prepositional Prototypes' in Pütz, M. \& R. Dirven (eds.) The Construal of Space in Language and Thought, Berlin/New York: Mouton de Gruyter, 135-165.

SANDRA, D. \& S. Rice 1995 'Network Analyses of Prepositional Meaning: Mirroring whose Mind - the Linguist's or the Language User's?' Cognitive Linguistics, 6-1, 89-130. 
Schulze, R. 1991 'Getting Round to (a)round: Towards the Description and Analysis of a "Spatial" Predicate', in G. Rauh (ed.) Approaches to Prepositions, Tübingen: Gunter Narr, 253-274.

-----1994 'Image Schemata and the Semantics of Off', in Schwarz, M. (ed.) Kognitive Semantik, Tübingen: Gunter Narr, 197-213.

Sinha, C. \& L. A. Thorseng, 1995, 'A Coding System for Spatial Relational Reference', Cognitive Linguistics, 6-2/3, 261-309.

Talmy, L. 1983 'How Language Structures Space' in Pick, H. \& L. Acredolo (eds.) Spatial Orientation: Theory, Research and Application, New York: Plenum Press, 225-281.

-----1988 'Force Dynamics in Language and Cognition' Cognitive Science, 12, 49-100.

TAYlor, J. R. 1989 Linguistic Categorization. Prototypes in Linguistic Theory, Oxford: Oxford University Press, reprinted 1992.

-----1993 'Prepositions: Patterns of Polysemization and Strategies of Disambiguation' in Zelinsky-Wibbelt, C. (ed.), The Semantics of Prepositions, Berlin: Mouton de Gruyter, 151-178.

-----1994 'Fuzzy Categories in Syntax: The Case of Possessives and Compounds in English' Rivista di Linguistica, vol. 6, no. 2, 327-345.

Vandeloise, C. 1991 Spatial Prepositions: A Case Study from French, Chicago: University of Chicago Press.

1994 'Methodology and Analyses of the Preposition in' Cognitive Linguistics, 5-2, 157-184. 